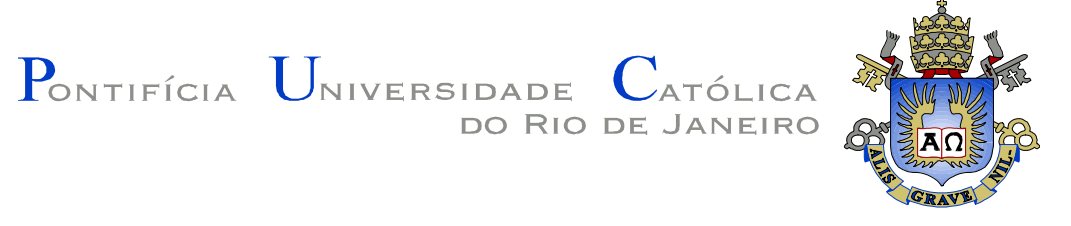

Isabel Cristina Fernandes Auler

As memórias de Carlos Lacerda.

Evocação de um passado presente

Dissertação de Mestrado

Dissertação apresentada como requisito parcial para obtenção do grau de Mestre pelo Programa de PósGraduação em História Social da Cultura do Departamento de História do Centro de Ciências Sociais da PUC-Rio.

Orientador: Prof. ${ }^{\circ}$ Luís Reznik

Rio de Janeiro

Abril de 2011 


\title{
As memórias de Carlos Lacerda. Evocação de um passado presente
}

Dissertação apresentada como requisito parcial para obtenção do grau de Mestre pelo Programa de PósGraduação em História Social da Cultura do Departamento de História do Centro de Ciências Sociais da PUC-Rio. Aprovada pela Comissão Examinadora abaixo assinada.

\author{
Prof. Luís Reznik \\ Orientador \\ Departamento de História \\ PUC-Rio
}

Profa. Márcia de Almeida Gonçalves

Departamento de História

PUC-Rio

Prof ${ }^{a}$ Marly Silva da Motta

Centro de Pesquisa e Documentação

FGV

Prof Mônica Herz

Vice-Decana de Pós-Graduação do Centro de Ciências Sociais

PUC-Rio

Rio de Janeiro, 05 de abril de 2011. 
Todos os direitos reservados. É proibida a reprodução total ou parcial do trabalho sem autorização do autor, do orientador e da universidade.

\section{Isabel Cristina Fernandes Auler}

Graduou-se em História pela Pontifícia Universidade Católica do Rio de Janeiro em 2008.

Ficha Catalográfica

Auler, Isabel Cristina Fernandes

As memórias de Carlos Lacerda : evocação de um passado presente / Isabel Cristina Fernandes Auler; orientador: Luís Reznik. - 2011. 110 f. ; $30 \mathrm{~cm}$

Dissertação (mestrado)-Pontifícia Universidade Católica do Rio de Janeiro, Departamento de História, 2011.

Inclui bibliografia

1. História - Teses. 2. Memória. 3. Projeto. 4. Identidade. 5. Evocação. 6. Retórica. 7. Lacerda. 2. História social da cultura. 3. Vaticano II. 4. América Latina. 5. Conferências gerais do CELAM. I. Reznik, Luís. II. Pontifícia Universidade Católica do Rio de Janeiro. Departamento de História. III. Título. 
Ao meu pai, Meu passado sempre presente.

Ao meu marido,

Minha promessa de um presente eterno. 


\section{Agradecimentos}

Ao meu orientador, Prof. Luis Reznik, por todo carinho e apoio na realização deste trabalho.

A CAPES e à PUC-Rio, pelo auxílio que tornou a realização deste trabalho possível. Aos professores e funcionários do departamento, pelos ensinamentos e pelo carinho. Aos meus amigos da PUC, em especial à minha querida cunhada Rebecca. Aos meus familiares, em especial à minha mãe, por toda compreensão e confiança. Ao meu marido Paulo, por todo amor. 


\section{Resumo}

Auler, Isabel Cristina Fernandes; Reznik, Luís. As Memórias de Carlos Lacerda. Evocação de um passado presente. Rio de Janeiro, 2011, 110 p. Dissertação de Mestrado - Departamento de História, Pontifícia Universidade Católica do Rio de Janeiro.

Sem perder de vista o constante diálogo entre memória, identidade e projeto, este trabalho analisa a obra de Carlos Lacerda, Rosas e Pedras de meu Caminho. O fio condutor reside na indagação sobre a maneira através da qual Lacerda elaborou tais narrativas em 1967, para torná-las coerentes com a visão que possuía e/ou pretendia apresentar de si neste período temporal. A concretização de seu projeto para o futuro, o qual consistiu em acelerar o processo de liberalização política para candidatar-se a Presidência da República, dependia dessa reconstrução de seu passado.

\section{Palavras-Chave}

Memória; projeto; identidade; evocação; retórica; Carlos Lacerda 


\section{Abstract}

Auler, Isabel Cristina Fernandes; Reznik, Luís. The memoirs of Carlos Lacerda. Evocation of a present past. Rio de Janeiro, 2011, 110 p. MSc. Dissertation - Departamento de História, Pontifícia Universidade Católica do Rio de Janeiro.

Without losing track of the constant dialogue between memory, identity and project, this work analysis Carlos Lacerda's book, Roses and Stones from my path. The main purpose of this study consists in verifying the way through which Lacerda elaborated such narratives in 1967, to make them consistent with the vision that he possessed - and/or wanted to present to the readers - of himself in this period of time. The realization of his project for the future, that consists of speeding up the process of democratization so he could participate on the next President elections, depends on his past's reconstruction.

\section{Keywords}

Memory; identity; project; rhetoric; Carlos Lacerda 


\section{Sumário}

1. Introdução.

1.1- Reivindicação de um lugar no palanque.

$\begin{array}{ll}\text { 1.2- Indecidibilidade versus Interminabilidade } & 15\end{array}$

1.3- Evocação como raiz da representação mimética. 20

2. Rememoração cambiante projetos viáveis.

2.1- A conjuntura política de 1964 a 1966: um projeto malogrado.

2.2- O projeto de 67: A Frente Ampla como resposta à prorrogação do governo militar.

2.3- Rosas e Pedras de meu caminho: a sincronia entre passado e presente.

3. A memória de geração.

Do valor familiar à herança política carioca.

4. A representação de si pela rejeição do outro.

Os conceitos antitéticos assimétricos e a manipulação retórica da linguagem política.

5. Conclusão.

6. Bibliografia 
A maior riqueza do homem é a sua incompletude. Nesse ponto sou abastado. Palavras que me aceitam como sou - eu não aceito.

Manoel de Barros,

Retrato do artista quando coisa. 